\title{
Dynamics of Verticillium Species Microsclerotia in Field Soils in Response to Fumigation, Cropping Patterns, and Flooding
}

\author{
Dylan P. G. Short, German Sandoya, Gary E. Vallad, Steven T. Koike, Chang-Lin Xiao, \\ Bo-Ming Wu, Suraj Gurung, Ryan J. Hayes, and Krishna V. Subbarao
}

First, seventh, and ninth authors: Department of Plant Pathology, and second author: The Genome Center and Department of Plant Sciences, University of California, Davis, 1636 E Alisal St., Salinas 93905; third author: Gulf Coast Research and Education Center, University of Florida, IFAS, Wimauma 33598; fourth author: University of California Cooperative Extension, 1432 Abbott Street, Salinas 93901; fifth author: United States Department of Agriculture-Agricultural Research Service (USDA-ARS), San Joaquin Valley Agricultural Sciences Center, 9611 S. Riverbend Ave, Parlier, CA 93648; sixth author: Department of Plant Pathology, China Agricultural University, Beijing 100193; and eighth author: USDA-ARS, 1636 E. Alisal St., Salinas, CA 93905.

Accepted for publication 6 January 2015.

\begin{abstract}
Short, D. P. G., Sandoya, G., Vallad, G. E., Koike, S. T., Xiao, C.-L., Wu, B.-M., Gurung, S., Hayes, R. J., and Subbarao, K. V. 2015. Dynamics of Verticillium species microsclerotia in field soils in response to fumigation, cropping patterns, and flooding. Phytopathology 105:638-645.

Verticillium dahliae is a soilborne, economically significant fungal plant pathogen that persists in the soil for up to 14 years as melanized microsclerotia (ms). Similarly, $V$. longisporum is a very significant production constraint on members of the family Brassicaceae. Management of Verticillium wilt has relied on methods that reduce ms below cropspecific thresholds at which little or no disease develops. Methyl bromide, a broad-spectrum biocide, has been used as a preplant soil fumigant for over 50 years to reduce $V$. dahliae ms. However, reductions in the number of $\mathrm{ms}$ in the vertical and horizontal soil profiles and the rate at which soil recolonization occurs has not been studied. The dynamics of $\mathrm{ms}$ in soil

before and after methyl bromide + chloropicrin fumigation were followed over 3 years in six 8 -by-8-m sites in two fields. In separate fields, the dynamics of $\mathrm{ms}$ in the 60 -cm-deep vertical soil profile pre- and postfumigation with methyl bromide + chloropicrin followed by various cropping patterns were studied over 4 years. Finally, ms densities were assessed in six 8-by-8-m sites in a separate field prior to and following a natural 6-week flood. Methyl bromide + chloripicrin significantly reduced but did not eliminate $V$. dahliae $\mathrm{ms}$ in either the vertical or horizontal soil profiles. In field studies, increases in ms were highly dependent upon the crop rotation pattern followed postfumigation. In the vertical soil profile, densities of $\mathrm{ms}$ were highest in the top 5 to $20 \mathrm{~cm}$ of soil but were consistently detected at $60-\mathrm{cm}$ depths. Six weeks of natural flooding significantly reduced (on average, approximately $65 \%$ in the total viable counts of $\mathrm{ms}$ ) but did not eliminate viable ms of V. longisporum.
\end{abstract}

Many soilborne fungi are capable of surviving the dynamic soil microenvironment through the formation of resilient resting structures, such as thick-walled spores, melanized hyphae, and sclerotia (6). Verticillium dahliae is a soilborne plant-pathogenic fungus that may persist in soil for up of 14 years in the absence of a host due to its ability to form melanized microsclerotia (ms) (27). Verticillium wilt disease caused by $V$. dahliae has been an economically significant problem on crops in the Salinas Valley for many decades but, on lettuce, it was first discovered in 1995 (1). Strawberry, artichoke, pepper, tomato, and lettuce are significantly affected by this disease in this area $(5,9,11,17)$. On cauliflower and other members of the Brassicaceae family, Verticillium wilt is caused by the related species $V$. longisporum (13). The inoculum density (number of propagules unit ${ }^{-1}$ mass of soil) is a significant epidemiological factor in Verticillium wilt (25). V. dahliae inoculum in soil may fluctuate over time due to chemical inputs (7), tillage (32), cropping patterns (34), and prolonged soil flooding $(12,26)$.

Management of Verticillium wilt is generally directed at reducing the density of viable ms to levels below the threshold at which the disease no longer develops (4), because Verticillium wilt development in different crops is associated with varying densities of viable ms (subsequent mentions of ms refer to viable $\mathrm{ms}$ ). In several crops, epidemics have been correlated with relatively low

Corresponding author: K. V. Subbarao; E-mail address: kvsubbarao@ucdavis.edu

http://dx.doi.org/10.1094/PHYTO-09-14-0259-R

(C) 2015 The American Phytopathological Society levels of ms. For example, 1 to $2 \mathrm{~ms} \mathrm{~g}^{-1}$ of soil resulted in $50 \%$ wilt incidence in strawberry (11), while cauliflower required $10 \mathrm{~ms} \mathrm{~g}^{-1}$ of soil to cause the same level of disease incidence (33). Verticillium wilt in peppermint (30), potato $(24,25)$, and artichoke (2) are also associated with relatively low levels of inoculum in soil. In contrast, during surveys of lettuce fields with approximately 5\% wilt incidence, estimates of densities were $16 \mathrm{~ms} \mathrm{~g}^{-1}$ of soil on average whereas, in fields with 80 and $94 \%$ wilt incidence, densities were estimated at 932 and $102 \mathrm{~ms} \mathrm{~g}^{-1}$ of soil, respectively (31), leading to the hypothesis that Verticillium wilt of lettuce occurs only when densities are higher than $100 \mathrm{~ms} \mathrm{~g}^{-1}$ of soil. Infested lettuce fields with up to $2,500 \mathrm{~ms} \mathrm{~g}^{-1}$ of soil have been reported (1).

Fumigation to reduce $V$. dahliae $\mathrm{ms}$ in soil has been widely practiced for decades in California (28). Methyl bromide (MeBr), a broad-spectrum biocide commonly used with chloropicrin (7), while being highly efficacious, does not completely sterilize soil $(7,15,28)$ and offers only transient pathogen reduction. Because it is recognized as a stratospheric ozone-depleting agent, it will finally be phased out from agricultural use in California by 2015 (28). Thus, it is important to quantify the effects of $\mathrm{MeBr}$ on pathogen distribution in fumigated soil and how the postfumigation cropping patterns affect this distribution. These results form the basis for comparing the efficacies of alternative fumigants currently registered for agricultural use and the potential of future innovative strategies to reduce Verticillium wilt.

A previous study (1) reported that three infested fields with approximately 150,40 , and $15 \mathrm{~ms} \mathrm{~g}^{-1}$ of soil treated with chloropicrin-telone, chloropicrin, and $\mathrm{MeBr}$, respectively, showed 
reductions in densities to less than $5 \mathrm{~ms} \mathrm{~g}^{-1}$ of soil following fumigation. All three fields experienced significant rebound in pathogen population growth when lettuce crops were grown 1 year postfumigation (1). However, multiyear quantitative data based on intensive sampling is needed to investigate the limitations of chemical fumigants and the effects of cropping patterns on changes in $V$. dahliae recolonization of soil postfumigation.

A limited number of multiyear studies have reported population fluctuations in $V$. dahliae in response to fumigation and cropping patterns (21). For example, a previous study has reported that fallow fields retain ms levels at near constant levels (4) and may be expected to decrease only slightly over time, whereas lettuce crops may cause ms levels to increase (1), consistent with reports of variable ms production on different crops (8). Preliminary data has recorded fluctuations from $10 \mathrm{~ms} \mathrm{~g}^{-1}$ of soil postfumigation to $>600 \mathrm{~ms}$ following two successive crops of lettuce (1). Conversely, there is evidence that broccoli cultivation suppresses the growth of $V$. dahliae in fields and actually leads to a decrease in soil ms levels over time (21).

In addition to chemical inputs, water submergence of field soils can greatly alter microbial soil communities, primarily by reducing available oxygen $(22,23)$, and has been investigated as a cultural control for managing pathogens. For example, flooding has been studied for its ability to destroy Sclerotinia $(16,19)$ and Leptosphaeria (22) reservoirs in fields. Previous investigations have revealed that cultivation of rice, millet, and sorghum under flooding can reduce $V$. dahliae in soil and reduce Verticillium wilt on subsequent crops $(4,9)$. Furthermore, the effectiveness of flooding as a cultural practice to reduce or eliminate $V$. dahliae from soil may be dependent on temperature (20). Flooding over a 12-week period successfully reduced $V$. dahliae to below detectable limits (26), and a 6-week flooding time has been estimated for successfully eliminating viable $V$. dahliae propagules in soil (18), based on limited small-scale experiments. Thus, as a strategy to reduce viable $\mathrm{ms}$, flooding has promise as a pathogen management technique if water resources and their use are unlimited.

Given the long-term persistence of $V$. dahliae in soil environments and the inevitable phase-out of $\mathrm{MeBr}$, it is critical to understand how $V$. dahliae populations vary over time so that the efficacy of alternative treatments or cultural practices, including flooding, can be sufficiently evaluated relative to MeBr. Knowledge of soilborne fungal dynamics, especially the "rebound" of soilborne pathogen populations, would also be useful to develop epidemiological models for soilborne diseases and make informed management decisions. Currently, multiyear quantifications of soil densities of $V$. dahliae are lacking, particularly in response to chemical fumigants, cropping patterns, and across different depths within the soil profile. Therefore, the objectives of the current study were to (i) determine the effects of fumigation on ms density in the horizontal soil profile, (ii) determine the dynamics of $\mathrm{ms}$ in the vertical soil profile postfumigation and under two cropping systems (fumigation followed by strawberry and continuous lettuce versus fumigation followed by strawberry and lettuce interspersed with cauliflower), and (iii) assess the effects of a 6-week natural flooding on ms densities within two different fields.

\section{MATERIALS AND METHODS}

Dynamics of ms densities in the horizontal soil profile. These studies were conducted in fields located in Watsonville, CA and both developed approximately $90 \%$ wilt incidence in 2004 on lettuce crops. Because of the near-total loss of lettuce crops, the grower decided to fumigate the fields with $\mathrm{MeBr}+$ chloropicrin (66: 33) at a rate of $393 \mathrm{~kg} \mathrm{~h}^{-1}$. Soils at all the experimental sites was an Elder sandy loam (coarse-loamy, mixed, thermic, Cumulic Haploxeroll) with $62 \%$ sand, $26 \%$ silt, $0.6 \%$ organic matter, and a $\mathrm{pH}$ of 6.5 . Soil samples were collected prior to fumigation in October to determine the distribution of $\mathrm{ms}$ in the horizontal profile in each field. Within each field, three 8-by-8-m grids of 64 contiguous quadrats ( 1 by $1 \mathrm{~m}$ ), separated by $75 \mathrm{~m}$, were demarcated and site locations were recorded using a GPS unit (Garmin, Schaffhausen, Switzerland). At each site, 64 prefumigation soil samples were collected in 2004 followed by an additional 64 postfumigation samples in 2005, 2006, and 2007 from the top 7 to $10 \mathrm{~cm}$ using a 6.25 -cm-diameter soil probe. Soil samples were assayed to determine the number of $\mathrm{ms}$ in each soil sample, as described below. Following fumigation, the cropping pattern in field 1 was strawberryromaine lettuce-crisphead lettuce and in field 2, the cropping sequence was strawberry-cabbage-crisphead lettuce.

Determination of $\boldsymbol{V}$. dahliae $\mathrm{ms}$ in soil samples. The number of $V$. dahliae $\mathrm{ms}$ in each sample was assayed by impaction plating of pulverized soil using the modified Anderson sampler technique (3), as previously described (32). Briefly, soil samples were placed in paper bags and air dried for 4 to 6 weeks on a greenhouse bench. Soil was pulverized with a mortar and pestle and sifted through a $0.425-\mathrm{mm}$ sieve. Soil $(10 \mathrm{~g})$ was placed in a snap-cap vial and mixed with $2.5 \mathrm{ml}$ of DL-methionine solution $\left(7.5 \mathrm{mg} \mathrm{ml}^{-1}\right)$ and incubated at $30^{\circ} \mathrm{C}$ for 1 week, then opened and air dried for 1 week at 22 to $24^{\circ} \mathrm{C}$. With the Anderson sampler, $0.5 \mathrm{~g}$ of pulverized soil was distributed on six petri plates containing NP-10 media $(3,13)$ and incubated at ambient indoor temperature in the dark. The numbers of $V$. dahliae colonies were counted 3 to 4 weeks after plating using a stereomicroscope. Counts from the six plates were combined as the number of colonies of $V$. dahliae per $0.5 \mathrm{~g}$ of soil and expressed as the number of $\mathrm{ms} \mathrm{g}^{-1}$ of dry soil.

The data were analyzed using SAS (version 9.3; SAS Institute, Cary, NC) to test the null hypothesis that the increase or decrease in $\mathrm{ms}$ densities over the years was different from zero. An unstructured covariance model was used and the covariance matrix was modeled using replicates nested within block and field. The $2004 \mathrm{~ms}$ data were used as a baseline and included in the model as a covariable. Each site was considered a block (three blocks per field) with 64 sampling points or replications (Figs. 1 and 2). Baseline, fields, time, and the field-time interaction were considered fixed factors, while blocks nested within fields were treated as random effects.

The $F$ value was used to detect significant effects in the analysis of variance (ANOVA) model, $P$ values $\leq 0.05$ were considered significant. Least square means (LSM) were calculated for each field in each year and compared between fields using the $P$ values. Two LSM were considered different when $P$ was at least $\leq 0.05$.

Vertical distribution of $\mathrm{ms}$ and soil recolonization following fumigation and cropping sequences. In fields located approximately $5 \mathrm{~km}$ away from those described above in 2002, lettuce crops also developed Verticillium wilt and resulted in a near-total yield loss. Because different cropping patterns were planned in these fields following fumigation (Table 1), fields were designated blocks 2, 3, 4, and $2 \mathrm{~L}$ to facilitate easier identification. Fields in both locations were owned by the same grower, who decided to fumigate these fields also with $\mathrm{MeBr}+$ chloropicrin at a rate of $393 \mathrm{~kg} \mathrm{~h}^{-1}$. Blocks 2, $2 \mathrm{~L}$, and 3 were fumigated in the fall of 2002 while block 4 was left as a nonfumigated control. Various crop rotations were followed in the blocks, as follows: block $2=$ strawberry (two seasons), fallow field, radicchio, fallow field, crisphead lettuce, romaine lettuce; block $3=$ strawberry (two seasons), fallow field, radicchio, fallow field, red cabbage, romaine lettuce; block 4 = strawberry (two seasons) fallow field, crisphead lettuce (three seasons), and cauliflower (Table 1); however, block $2 \mathrm{~L}$ was a low-lying part of the field that was too wet to plant crops and, thus, was left fallow for the duration of this study. Each spring from 2002 (prefumigation samples) to 2005 (postfumigation samples to determine soil recolonization), 48 soil samples (12 samples from four sites) were collected in each block in $5-\mathrm{cm}$ increments to a depth of $60 \mathrm{~cm}$ using a $6.25-\mathrm{cm}$-diameter soil probe. Sampling sites were geo-referenced to obtain yearly samples in the vicinity of these locations. The number of $\mathrm{ms}$ in each soil sample was determined using the technique described above. 


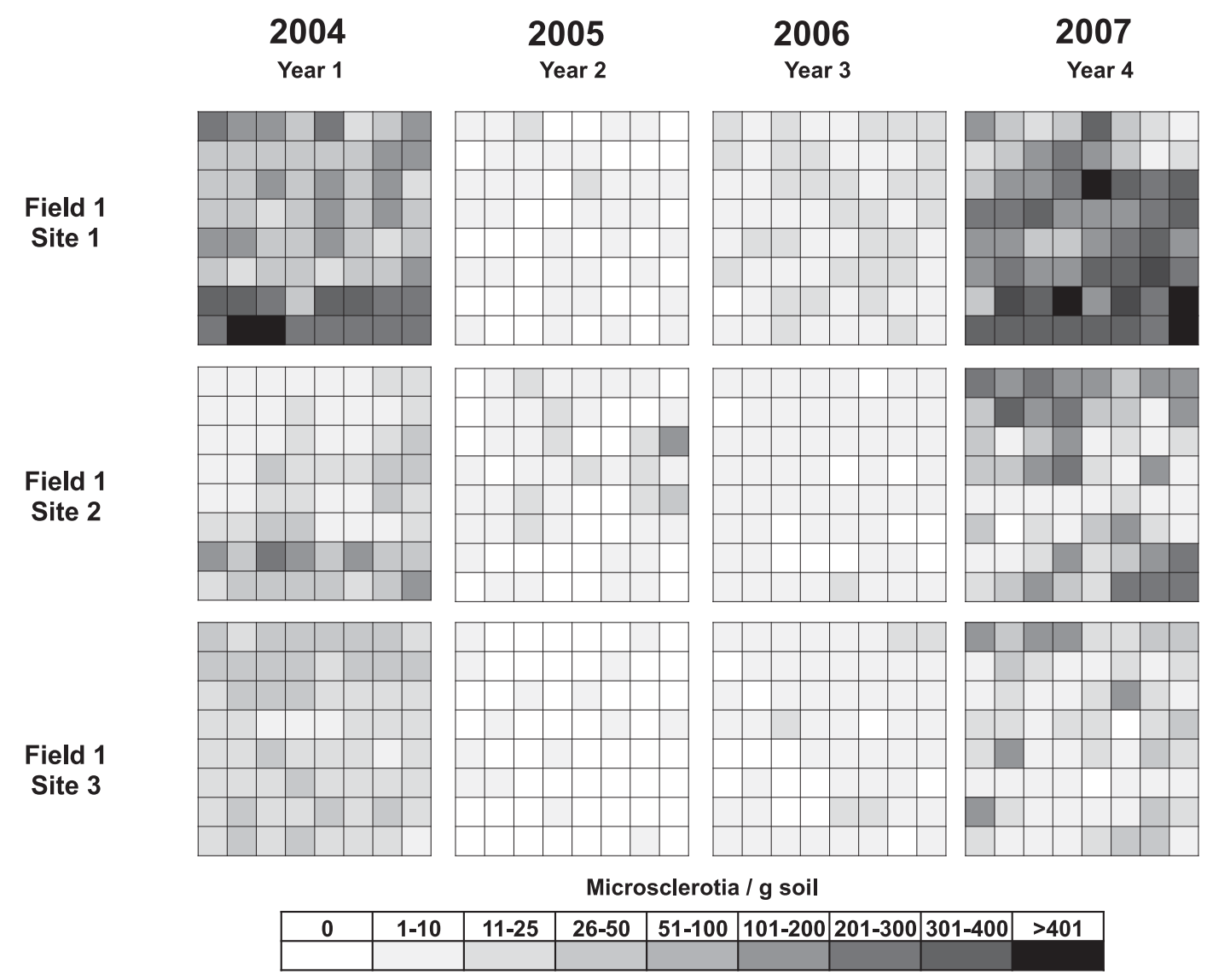

Fig. 1. Verticillium dahliae microsclerotia $\mathrm{g}^{-1}$ of soil estimates for field 1 over the 4-year study period near Watsonville, CA.

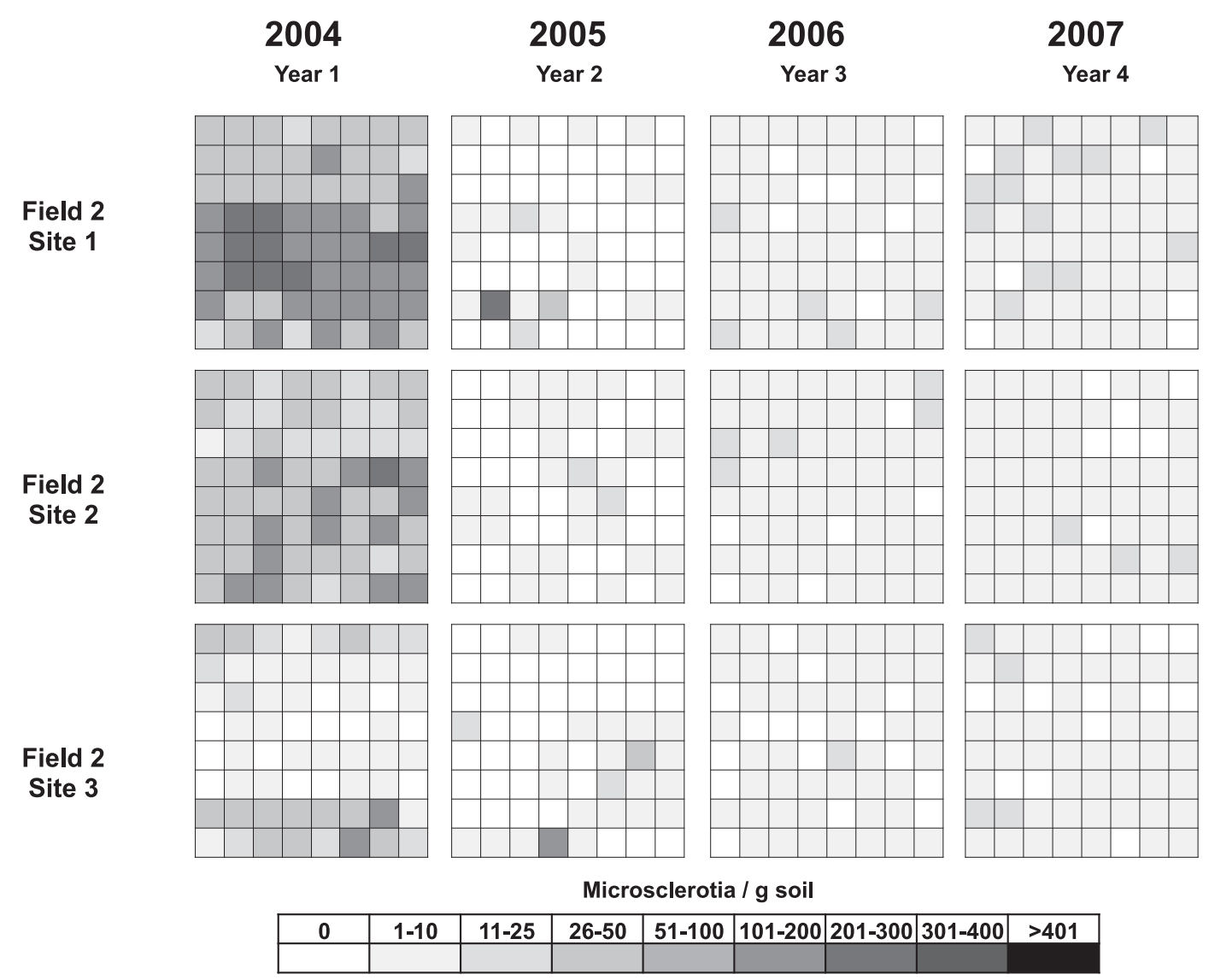

Fig. 2. Verticillium dahliae microsclerotia $\mathrm{g}^{-1}$ of soil estimates for field 2 over the 4-year study period near Watsonville, CA. 
The differences in the levels of $\mathrm{ms}$ in different blocks and depths over time were analyzed using a repeated measures ANOVA in PROC MIXED in SAS (version 9.3; SAS Institute) following Littell et al. (2006) (14). An autoregressive order 1 covariance structure was used. The $2002 \mathrm{~ms}$ data were used as a baseline and fit in the model as a covariable. In the ANOVA, baseline, blocks, depths, and times were considered fixed effects.

LSM were calculated for each depth-year-block treatment combination. When interactions were significant, differences in the main treatment levels were tested for significance using the SAS "slice" option at $P \leq 0.05$. Three types of comparison were made. The first compared the differences between years within each block and soil depth. In the second, differences among soil depths within each block and year were compared. The third comparison was made between blocks within each depth and year. Because the cropping sequences influenced ms densities within each block, the recolonization of soil postfumigation by $V$. dahliae was directly related to the ms densities within each block.

Changes in $V$. longisporum $\mathrm{ms}$ density in response to flooding. Three study sites were demarcated in each of two fields infested with $V$. dahliae, designated A and B. Each site was divided into 64 contiguous 1-by-1-m quadrats. The cropping pattern of these fields at the time of study consisted of cauliflower in annual rotation with lettuce. In the Salinas Valley, CA, intense flooding occurred in January and March 1995 as a result of significant winter storms, which left standing water on saturated fields for 4 weeks. Significant precipitation also occurred subsequent to the peak periods of winter storms. After standing water had drained, fields remained too wet for tillage operations for an additional 3 to 4 weeks. Therefore, the fields were under flooded conditions for at least 6 weeks. Soil cores were collected to a depth of $15 \mathrm{~cm}$ with a 2.5 -cm-diameter soil probe preflooding (31) and postflooding (an additional 6 weeks after the flooding period ended) from the same quadrats. The number of $V$. dahliae $\mathrm{ms}$ in each sample was assayed as described above.

Differences between ms densities preflooding and postflooding were computed using an ANOVA with the MIXED procedure of SAS (version 9.3; SAS Institute). Flooding status (pre and post), fields, and flood-field were considered fixed factors, whereas the interaction of block (flooding-field) was considered a random factor. Means (LSM) were computed and were considered significantly different when $P$ was at least $\leq 0.05$.

\section{RESULTS}

Densities of $\mathrm{ms}$ in response to fumigation in the horizontal soil profile. Both lettuce fields used in this study had up to $90 \%$ wilt incidence (in the area where the sampling locations were demarcated) in the lettuce crops in 2004 and contained high but unequal amounts of $\mathrm{ms}$ prior to fumigation. Field $1 \mathrm{had}$ an average of $46 \mathrm{~ms} \mathrm{~g}^{-1}$ of soil and field 2 contained a mean of $38 \mathrm{~ms} \mathrm{~g}^{-1}$ of soil. The use of the 2004 data as a baseline was done to adjust the analysis for the unbalanced ms levels at the beginning of the experiment (Table 2$)$, and this was statistically significant $(P=$

TABLE 1. Postfumigation cropping history in the four blocks of a field infested by Verticillium dahliae at the beginning of the vertical soil profile study

\begin{tabular}{|c|c|c|c|c|c|c|c|c|}
\hline \multirow[b]{2}{*}{ Block } & \multicolumn{2}{|c|}{2002} & \multicolumn{2}{|c|}{2003} & \multicolumn{2}{|c|}{2004} & \multicolumn{2}{|c|}{2005} \\
\hline & Spring* & Fall & Spring* & Fall & Spring* & Fall & Spring* & Fall \\
\hline 2 & CL & F-St & St & - & Radi & - & CL & RoL \\
\hline $2 \mathrm{~L}$ & CL & F & - & - & - & - & - & - \\
\hline 3 & CL & F-St & St & - & Radi & - & RCab & RoL \\
\hline 4 & CL & NF-St & St & - & CL & CL & CL & $\mathrm{Cau}$ \\
\hline
\end{tabular}

a Asterisks $(*)$ indicate sampling times, $-=$ fallow field, $\mathrm{F}=$ fumigation, $\mathrm{NF}=$ nonfumigation, $\mathrm{CL}=$ crisphead lettuce, $\mathrm{RoL}=$ romaine lettuce, Radi $=$ radicchio, $\mathrm{St}=$ strawberry, cau $=$ cauliflower, $\mathrm{GCab}=$ green cabbage, and Rcab $=$ Red cabbage.
0.0006) (Table 2). In the ANOVA, differences between fields were not significant $(P=0.1515)$, whereas time and the time-field interaction were highly significant $(P>0.0001)$ (Table 2$)$. In both fields, fumigation reduced but did not completely eliminate detectable levels of $V$. dahliae ms (Figs. 1 and 2). After fumigation, the levels of $\mathrm{ms}$ in both fields was reduced to approximately $3 \mathrm{~ms} \mathrm{~g}^{-1}$ of soil (Table 3). Both fields were planted to strawberry following fumigation and there was a small increase in the number of $\mathrm{ms}$ to approximately $5 \mathrm{~ms} \mathrm{~g}^{-1}$ of soil in 2006 (Table 3 ). The cropping patterns of the two fields up until then were identical and the mean number of $\mathrm{ms} \mathrm{g}^{-1}$ of soil was not significantly different in 2005 $(P=0.9680)$ or $2006(P=0.9509)$ (Table 3$)$. However, in field 1 , romaine lettuce was cultivated in 2007 and average inoculum density increased to $75 \mathrm{~ms} \mathrm{~g}^{-1}$ of soil. In field 2, a cabbage crop was grown instead and only $6 \mathrm{~ms} \mathrm{~g}^{-1}$ of soil were found (Table 3 ). The mean number of ms per gram of soil in the two fields in 2007 was significantly different $(P=0.0048)$. The inoculum distribution in the horizontal soil profile over time in field 1 was approximated by the distribution of ms prior to fumigation in all three sites, although some slight differences in the redistribution of soil ms was apparent, which could be attributed to soil tillage practices (Fig. 1). In contrast, the distribution of ms postfumigation was maintained for at least 2 years following fumigation in field 2 (Fig. 2).

Vertical distribution of ms pre- and postfumigation. The inoculum distribution in the vertical soil profile was evaluated in fields with a history of Verticillium wilt in lettuce crops. Prior to fumigation in 2002, the levels of ms were different in each block regardless of the depth (data not shown). In addition, the amounts of $\mathrm{ms}$ in 2002 prior to fumigation were higher than in subsequent years (2003, 2004, and 2005) (data not shown). Therefore, the 2002 data were used as a baseline in the model, which was significantly higher than in all other years $(P<0.0001)$. Blocks, depths, time, and their interactions were also significant $(P<0.0001)$ in the ANOVA (Table 4). LSM of ms differed among years in blocks 2,3 , and 4 at depths of $5 \mathrm{~cm}$ (Table 5). Differences between years were detected at greater depths in block $2(5,10,15,20,25$, and $35 \mathrm{~cm})$ and block 3 $(5,10,15,20,25$, and $30 \mathrm{~cm})$ (Fig. 3). Overall, the highest amounts of ms were found in 2004 in blocks 2 and 3 (Table 5). There were no differences in the numbers of ms at any soil depth in block $2 \mathrm{~L}$ (Table 5). The nonfumigated block 4 initially (2002) had lower numbers of ms compared with blocks 2 and 3 (data not shown) and

TABLE 2. Repeated measures analysis of variance for the level of microsclerotia in two different field sites in Salinas, CA with different cropping histories

\begin{tabular}{lcccr}
\hline Effect $^{\mathrm{a}}$ & Num DF & Den DF & $F$ value & \multicolumn{1}{c}{$P>F^{\mathrm{b}}$} \\
\hline Baseline & 1 & 343 & 12.09 & 0.0006 \\
Fields & 1 & 3.96 & 3.15 & 0.1515 \\
Times & 2 & 593 & 92.26 & $<0.0001$ \\
Times $\times$ fields & 2 & 593 & 82.97 & $<0.0001$ \\
\hline
\end{tabular}

a Baseline data were microsclerotia from 2004 and times represent the response of the microsclerotia over the years $(2005,2006$, and 2007).

b Differences significant at $P \leq 0.05$.

TABLE 3. Least square means of the level of microsclerotia in three different years (2005 to 2007) at two different field sites in Watsonville, CA with different cropping histories

\begin{tabular}{lllc}
\hline & \multicolumn{3}{c}{ Years $^{\mathrm{a}}$} \\
\cline { 2 - 4 } Fields $^{\mathrm{b}}$ & 2005 & 2006 & 2007 \\
\hline Field 1 & 2.94 & 5.66 & 75.21 \\
Field 2 & 3.51 & 4.77 & 5.94 \\
$P$ value & 0.968 & 0.9509 & 0.0048 \\
\hline
\end{tabular}

a Means are the average of 192 sampling points each year and field.

b Both fields were fumigated in 2004. Field 1 was planted with strawberry (2005), crisphead lettuce (2006), and romaine lettuce (2007). Field 2 was planted with strawberry (2005), crisphead lettuce (2006), and cabbage (2007). 
generally did not have significant changes in ms, with the exception of an increase at $5 \mathrm{~cm}$ in 2005 (Table 5). At increasing soil depths, ms decreased in blocks 2 and 3, beginning in 2004 (Table 5). The reductions were significant in all years for block 2 and in 2003 and 2004 for block 3. Differences between blocks were observed and the highest ms were generally observed in blocks $2(P \leq 0.0001$ in 2003, 2004, and 2005) and 3 ( $P \leq 0.0001$ in 2003 and 2004); no significant differences were observed in block 3 in $2005(P=0.9595)$ or blocks $2 \mathrm{~L}(P=1,0.9966$, and 1 in 2003, 2004, and 2005, respectively) and block 4 ( $P=0.9976,0.9991$, and 0.2328 in 2003, 2004, and 2005, respectively). Differences between blocks were detected at a depth of $5 \mathrm{~cm}$ in all years. Significant differences between blocks were detected down to 35 and $45 \mathrm{~cm}$ in 2004 (Table 6) and at 5, 10, 15, and $25 \mathrm{~cm}$ in 2005 (Table 6).

Changes in $V$. longisporum $\mathrm{ms}$ density and field distribution in response to flooding. Preflooding sampling conducted across fields A and B in six different blocks indicated that $\mathrm{ms}$ distributions were not equal within each field. Field A had higher densities of ms than field B (Fig. 4). The postflooding soil distributions of ms were also not equal in both fields. The analysis of variance showed significant differences in the levels of ms due to flooding (Table 7). Differences between fields were not significant, whereas the flooding-field interaction was significant $(P=0.0077)$. A higher reduction of $\mathrm{ms}$ was detected in field A (63\%) than in field B (14\%); ms were detected in all six blocks after flooding (Fig. 4). The level of $\mathrm{ms}$ was reduced postflooding but not eliminated in either field. The LSM of the levels of ms from both fields, based on 384 sampling points from both field sites, were $21.94 \mathrm{~ms} \mathrm{~g}^{-1}$ of soil before flooding and $7.32 \mathrm{~ms} \mathrm{~g}^{-1}$ of soil after flooding, with a $P$ value of 0.0008 .

\section{DISCUSSION}

Understanding the dynamics of fungal population fluctuations in soil in response to abiotic factors, including chemical inputs, is

TABLE 4. Repeated measures analysis of variance for the level of microsclerotia sampled in four block at 12 depths between 5 and $60 \mathrm{~cm}$ between 2003 and 2005

\begin{tabular}{lcccr}
\hline Effect & Num DF & Den DF & $F$ value & $P>F$ \\
\hline Baseline $^{\mathrm{a}}$ & 1 & 148 & 25 & $<0.0001$ \\
Block $^{\mathrm{b}}$ & 3 & 105 & 62.88 & $<0.0001$ \\
Depth & 11 & 177 & 8.5 & $<0.0001$ \\
Time & 2 & 239 & 9.07 & 0.0002 \\
Depth $\times$ block & 33 & 175 & 3.03 & $<0.0001$ \\
Time $\times$ block & 6 & 239 & 8.38 & $<0.0001$ \\
Time $\times$ depth & 22 & 277 & 3.93 & $<0.0001$ \\
Time $\times$ depth $\times$ block & 66 & 266 & 1.95 & 0.0001 \\
\hline
\end{tabular}

a Data from 2002 were used as a baseline, which was introduced into the model as a covariable.

b Three blocks were fumigated blocks while one was not fumigated. important for sustainable management of recalcitrant soilborne pathogens such as $V$. dahliae. Knowledge of how fungal inoculum changes over time is important to estimate the potential disease pressure, based on which, cropping decisions can be made. In this study, we determined the effects of fumigation on the ms densities in both the horizontal and vertical soil profiles and also determined how these densities are affected by cropping practices and a natural flooding event.

In the first experiment, soils from two fields were sampled prior to fumigation and during subsequent seasons to monitor and map V. dahliae ms levels in the soil. As expected, dramatic decreases in $\mathrm{ms}$ densities were observed in the three sites within both fields following fumigation with $\mathrm{MeBr}$ and chloropicrin. A year after fumigation, the majority of samples contained no detectable ms. Over time, the counts of viable ms increased, suggesting that the V. dahliae population had reproduced on subsequent crops. Up until the third sampling, the two fields followed identical cropping patterns but, after the third sampling, field 1 was planted with romaine lettuce whereas field 2 was planted with cauliflower. This difference in a single crop between the third and fourth sampling times appears to have played a critical role in the increase of $V$. dahliae within field soil because $V$. dahliae is not pathogenic on cauliflower (32). In all three sites in field 2 before and after cauliflower, ms densities were not significantly different. In contrast, ms densities in all three sites in field 1 showed significant increases over soils sampled prior to the romaine lettuce crop. Within the lettuce field, there was strong evidence that soil levels of $\mathrm{ms}$ had increased back to the prefumigation levels. We attribute these differences to the cropping pattern itself, and deduce that lettuce enabled the fungus to rapidly reestablish within the soil, relative to cauliflower. Cauliflower and lettuce both develop Verticillium wilt but the causal agents in the two crops are different. Although Verticillium wilt in lettuce is caused by $V$. dahliae, in cauliflower it is caused by the sister species V. longisporum (13), and the two species are not cross-pathogenic on the two crops (32). Thus, even if one species is present in the soil, planting the nonhost species does not augment the soil inoculum levels and, thus, the results of this experiment strongly suggest that production of $\mathrm{ms}$ in lettuce by $V$. dahliae was significantly greater than on cauliflower.

These results indicate that fumigation with $\mathrm{MeBr}+$ chloropicrin significantly reduced but did not eliminate $\mathrm{ms}$ below the detection limit of $<2 \mathrm{CFU} / \mathrm{g}$ of soil. We estimated that multiple samples in different replicates and experiments contained between 50 and $100 \mathrm{~ms} \mathrm{~g}^{-1}$ of soil following fumigation, which, according to models of $V$. dahliae epidemiology, would be over the predicted threshold for disease development in all crops studied to date, except lettuce (31). There is evidence that sites with high initial levels of $\mathrm{ms}$ experience faster rebounds of $\mathrm{ms}$ in soil (31). Furthermore, it appears that some crops, especially lettuce, play an important role in providing conducive environments for the

TABLE 5. Least square means of the level of microsclerotia in three different years (2003 to 2005) after fumigation, in blocks ${ }^{\mathrm{a}}$

\begin{tabular}{|c|c|c|c|c|c|c|c|c|c|c|c|c|c|c|c|c|}
\hline \multirow[b]{2}{*}{ Depths } & \multicolumn{4}{|c|}{ Block $2 \mathrm{~L}$} & \multicolumn{4}{|c|}{ Block 2} & \multicolumn{4}{|c|}{ Block 3} & \multicolumn{4}{|c|}{ Block 4} \\
\hline & 2003 & 2004 & 2005 & $P$ value & 2003 & 2004 & 2005 & $P$ value & 2003 & 2004 & 2005 & $P$ value & 2003 & 2004 & 2005 & $P$ value \\
\hline 5 & 6.8 & 3.1 & 7.1 & 0.8862 & 102.0 & 42.0 & 44.5 & $<0.0001$ & 66.4 & 45.9 & 5.9 & $<0.0001$ & 7.4 & 6.1 & 27.6 & 0.0252 \\
\hline 10 & 6.1 & 2.3 & 5.8 & 0.8996 & 18.7 & 45.0 & 49.0 & 0.0011 & 12.0 & 43.5 & 12.0 & 0.0004 & 6.7 & 4.9 & 18.9 & 0.2284 \\
\hline 15 & 4.7 & 9.9 & 4.7 & 0.8017 & 7.7 & 43.7 & 36.2 & 0.0001 & 16.9 & 46.4 & 15.4 & 0.0008 & 11.1 & 6.3 & 7.9 & 0.8626 \\
\hline 20 & 4.6 & 10.3 & 4.3 & 0.7580 & 14.0 & 37.2 & 24.7 & 0.0376 & 21.6 & 52.8 & 14.3 & $<0.0001$ & 8.5 & 9.8 & 4.8 & 0.843 \\
\hline 25 & 5.1 & 4.6 & 3.4 & 0.9789 & 12.6 & 45.8 & 25.3 & 0.0013 & 8.3 & 39.1 & 10.6 & 0.0010 & 9.6 & 8.6 & 2.6 & 0.6892 \\
\hline 30 & 4.1 & 2.4 & 3.4 & 0.9813 & 7.9 & 19.1 & 15.6 & 0.4365 & 10.8 & 31.1 & 9.12 & 0.0287 & 4.8 & 6.3 & 5.8 & 0.9855 \\
\hline 35 & 2.2 & 2.5 & 3.7 & 0.9833 & 3.7 & 26.0 & 19.0 & 0.0405 & 11.6 & 23.4 & 18.4 & 0.4232 & 4.9 & 4.1 & 6.1 & 0.9749 \\
\hline 40 & 5.3 & 3.1 & 3.3 & 0.9619 & 3.3 & 18.3 & 15.3 & 0.2044 & 9.6 & 12.4 & 9.9 & 0.9458 & 3.1 & 1.1 & 10.1 & 0.5689 \\
\hline 45 & 3.8 & 2.8 & 5.3 & 0.9614 & 3.5 & 24.7 & 23.7 & 0.0263 & 9.3 & 8.6 & 5.6 & 0.9024 & 4.6 & 2.8 & 8.8 & 0.7873 \\
\hline 50 & 4.3 & 3.0 & 6.0 & 0.9452 & 7.0 & 10.0 & 25.0 & 0.0909 & 6.9 & 7.4 & 7.6 & 0.9962 & 7.9 & 3.4 & 10.9 & 0.7064 \\
\hline 55 & 4.4 & 3.4 & 6.4 & 0.9433 & 4.7 & 18.9 & 3.4 & 0.1698 & 7.3 & 7.3 & 11.8 & 0.8405 & 9.0 & 3.8 & 9.8 & 0.7731 \\
\hline 60 & 2.7 & 2.5 & 3.0 & 0.9985 & 8.1 & 9.4 & 21.4 & 0.2516 & 3.1 & 4.9 & 8.4 & 0.8291 & 2.2 & 3.7 & 4.7 & 0.9592 \\
\hline
\end{tabular}

${ }^{\text {a }}$ Block $2 \mathrm{~L}=$ not fumigated, blocks 2 and $3=$ fumigated, and block $4=$ controls. $P$ values are the effect of years within each soil depth for each block. 
fungus to reproduce rapidly and reach epidemiologically relevant levels under favorable conditions.

The modes of action of $\mathrm{MeBr}+$ chloropicrin are not precisely known. Therefore, it remains to be seen whether residual $V$. dahliae in fumigated fields are somehow phenotypically more resilient to exposure to these chemicals or are the result of inefficient vapor penetration throughout the vast soil micropore matrix. We have demonstrated that pockets of $V$. dahliae reservoirs may remain in field soil following fumigation, and that these events represent population bottlenecks which drastically reduce $V$. dahliae population genetic diversity. This is supported by the fact that $V$. dahliae populations in the Salinas Valley are dominated by only a few widespread genotypes which have been prevalent since 1995 (10).

In the second experiment, we explored the dynamics of $V$. dahliae $\mathrm{ms}$ densities in the vertical soil profile as influenced by fumigation and differences in postfumigation cropping patterns. The relationship between Verticillium wilt incidence and densities of ms follows a threshold of approximately $150 \mathrm{~ms} \mathrm{~g}^{-1}$ of soil for lettuce crops to develop significant levels of wilt (31). The prefumigation densities of ms in block 2 was in line with this inoculum threshold, because $90 \%$ incidence was correlated with an average of $493 \mathrm{~ms} \mathrm{~g}^{-1}$ of soil. In contrast, block $2 \mathrm{~L}$, which had levels of Verticillium wilt incidence similar to those in block 2, contained less than $10 \mathrm{~ms} \mathrm{~g}^{-1}$ of soil. Block $2 \mathrm{~L}$ was located in a lower part of the field with stagnant water, and this may have reduced the number of $\mathrm{ms}$ in this block. The wilt incidence in block 3 , estimated to be between 10 and $15 \%$, was correlated with $66 \mathrm{~ms} \mathrm{~g}^{-1}$ of soil whereas block 4 , which had no wilt, contained approximately $28 \mathrm{~ms} \mathrm{~g}^{-1}$ of soil, again validating the inoculum threshold required for high incidence of Verticillium wilt in lettuce (31). These studies did not take into account the pathogenic races present in the soil. Preliminary evidence from field inoculation studies suggest that the fecundity of race 1 reference strain $V$. dahliae Ls16 is much higher than that of race 2 reference strain $V$. dahliae Ls17 when inoculated into
'Salinas' lettuce. Soils from a field planted with Ls16-inoculated plants contained much higher viable ms densities following a season of crop growth compared with the a neighboring field planted with Ls17-inoculated plants (K. V. Subbarao, unpublished data). Further studies are needed to determine the variability in inoculum production and associated disease incidence among strains of $V$. dahliae belonging to races 1 and 2 .

In blocks 2 and 3, the cropping patterns were similar, except during the spring of 2005, when crisphead lettuce was grown in block 2 and red cabbage was grown in block 3 instead. The combination of higher wilt incidence prior to fumigation in block 2 , consistently higher soil inoculum densities, and planting of successive susceptible crops influenced the increase in $V$. dahliae ms across all depths relative to block 3 . In contrast, in block 4 , lack of disease in 2002 and low levels of ms across all depths were kept low through 2005 despite the planting of susceptible crops throughout the study, except in the fall of 2005. As demonstrated

TABLE 6. Probability values from the 'slice' option in SAS for the effect of block on microsclerotia within each depth and year

\begin{tabular}{lccc}
\hline & \multicolumn{3}{c}{ Years } \\
\cline { 2 - 4 } Depths & 2003 & 2004 & 2005 \\
\hline 5 & $<0.0001$ & $<0.0001$ & $<0.0001$ \\
10 & 0.4587 & $<0.0001$ & $<0.0001$ \\
15 & 0.5332 & $<0.0001$ & 0.0019 \\
20 & 0.2341 & $<0.0001$ & 0.0673 \\
25 & 0.8621 & $<0.0001$ & 0.0336 \\
30 & 0.858 & 0.004 & 0.525 \\
35 & 0.7127 & 0.0073 & 0.1684 \\
40 & 0.8646 & 0.1633 & 0.5951 \\
45 & 0.8992 & 0.0383 & 0.1124 \\
50 & 0.9783 & 0.829 & 0.1168 \\
55 & 0.9431 & 0.2452 & 0.7824 \\
60 & 0.8962 & 0.868 & 0.1409 \\
\hline
\end{tabular}
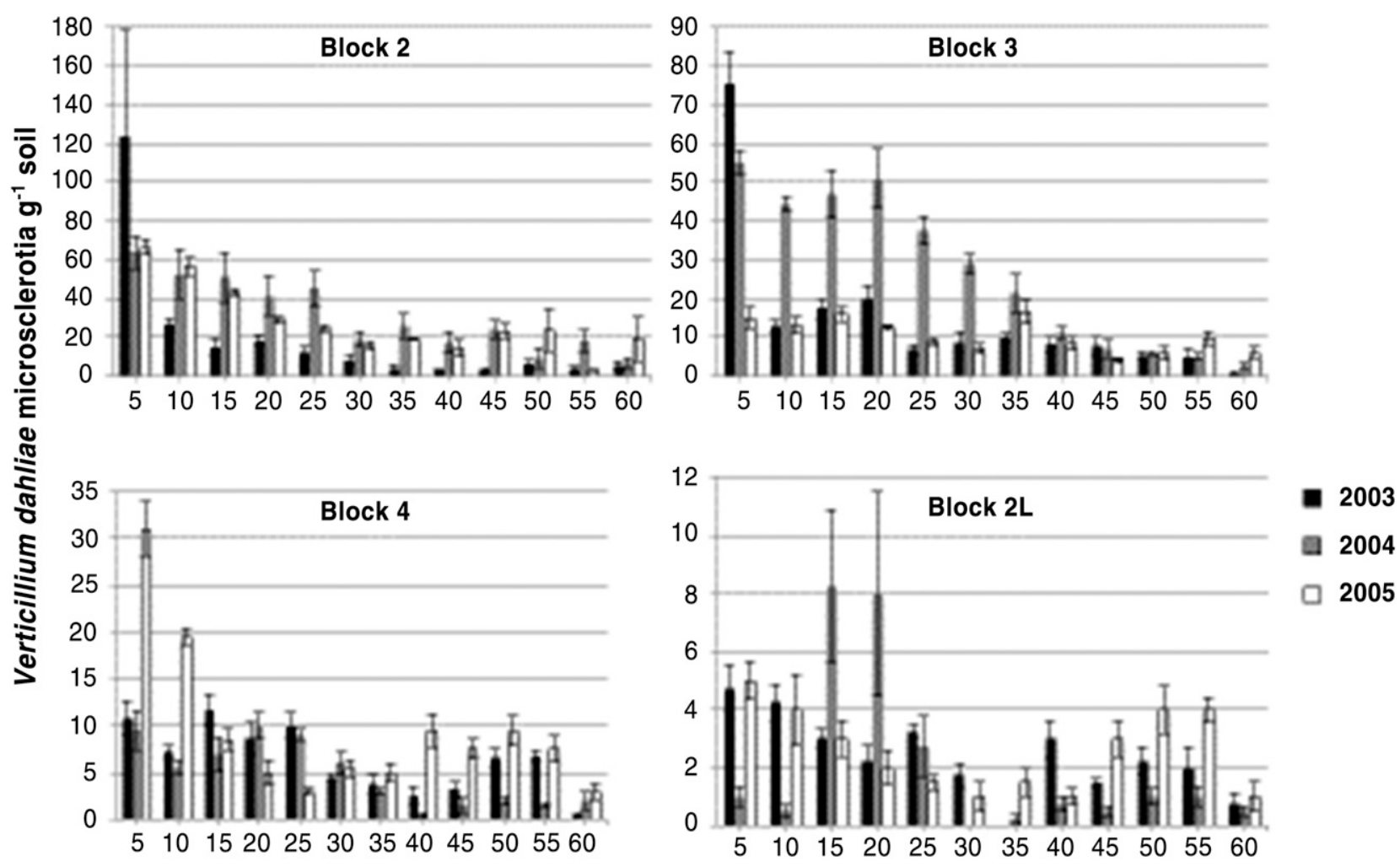

Soil depth $(\mathrm{cm})$

Fig. 3. Verticillium dahliae microsclerotia $\mathrm{g}^{-1}$ of soil estimates from 5 to $60 \mathrm{~cm}$ within blocks 2,3 , 4, and $2 \mathrm{~L}$. Standard errors are shown with error bars. 
in the postfumigation increase in $V$. dahliae $\mathrm{ms}$ in the horizontal soil profile, the cropping patterns critically influenced the dynamics of $V$. dahliae $\mathrm{ms}$ in the vertical soil profile as well.

The presence of inoculum at depths where plant roots grow is one of the most epidemiologically relevant factors, and different crops may be affected by pathogens present at different depths owing to differences in plant root architecture. Generally speaking, when the data from all four blocks were combined from the second experiment, the top $5 \mathrm{~cm}$ consistently contained the highest $\mathrm{ms}$ densities, and the top 5 to 15 or $20 \mathrm{~cm}$ likewise contained significantly higher numbers of $\mathrm{ms}$ than deeper depths. The presence of greater numbers of $\mathrm{ms}$ near the soil surface is presumably due to the growth and reproduction of $V$. dahliae on plant roots and on debris in the top $25 \mathrm{~cm}$ of the soil profile. The root architecture of lettuce, in particular $(15,16)$, may represent a highly conducive niche for reproduction among the diverse hosts of $V$. dahliae because much of the root biomass (taproot and the extensive adventitious root system) is located within the raised beds. Even at $60 \mathrm{~cm}$ of depth, ms were consistently detected in all the blocks, which suggests that tillage of soil may mechanically disperse ms from soil depths near the surface to deeper depths.

Soil tillage also plays a role in moving $\mathrm{ms}$ across fields, because we observed a reduction in ms in multiple sections of the vertical soil profile within a nonfumigated control site. This is attributable to the dispersal of $\mathrm{ms}$ from the sampling site via tillage, as well as natural local-level dispersal. Taken with the observation that rare patches of residual ms remain in fields, the movement of ms via tillage may allow $V$. dahliae populations to reestablish more quickly, because more ms are spread to areas planted with host crops. This observation is in-line with recent population genetics analyses of $V$. dahliae in the Salinas Valley, CA, which revealed persistent, widespread, highly clonal populations in commercial fields (10), consistent with the idea of clonets arising from point source reservoirs of recalcitrant genotypes. Although fumigation may significantly reduce most $V$. dahliae within infested field sites, it may also drive population bottlenecks and inadvertently select for recalcitrant genotypes to subsequently infect and dominate the rhizosphere.

Verticillium has been reported to survive incubation under anaerobic conditions (8), which would theoretically allow survival of $\mathrm{ms}$ beyond the initial period of oxygen depletion that occurs in soil submergence (23). A previous report found that 6 weeks of flooding were required to decrease ms densities in soil (26), which fell from 50 to 60 to 0 to $10 \mathrm{~ms} \mathrm{~g}^{-1}$ of soil over the course of 17 weeks. Based on these observations, Pullman and DeVay (26) hypothesized that Verticillium ms may withstand flooding conditions for up to 6 weeks, due to their resilient, multicellular nature. In the current study, after a 6-week period of stagnant flood waters, three sites experienced, on average, approximately $65 \%$ reduction in counts of viable ms. In several sampled quadrats in five of the six sites, ms were not detected. However, the majority of quadrats still contained 6 to $45 \mathrm{~ms} \mathrm{~g}^{-1}$ of soil. Temperature effects on the efficacy of flooding in reducing Verticillium ms have also been reported $(20,26)$; in the current study,

TABLE 7. Analysis of variance for the number of microsclerotia before and after flooding in two different field sites in Salinas, CA during 1995

\begin{tabular}{lccrc}
\hline Effect & Num DF & Den DF & $F$ value & $P>F^{\text {a }}$ \\
\hline Flooding & 1 & 6 & 37.97 & 0.0008 \\
Fields & 1 & 6 & 2.00 & 0.2072 \\
Flooding $\times$ field & 1 & 6 & 15.44 & 0.0077 \\
Rep (block) & 189 & 268 & 1.07 & 0.3135 \\
\hline
\end{tabular}

a Significant differences $(P \leq 0.05)$.

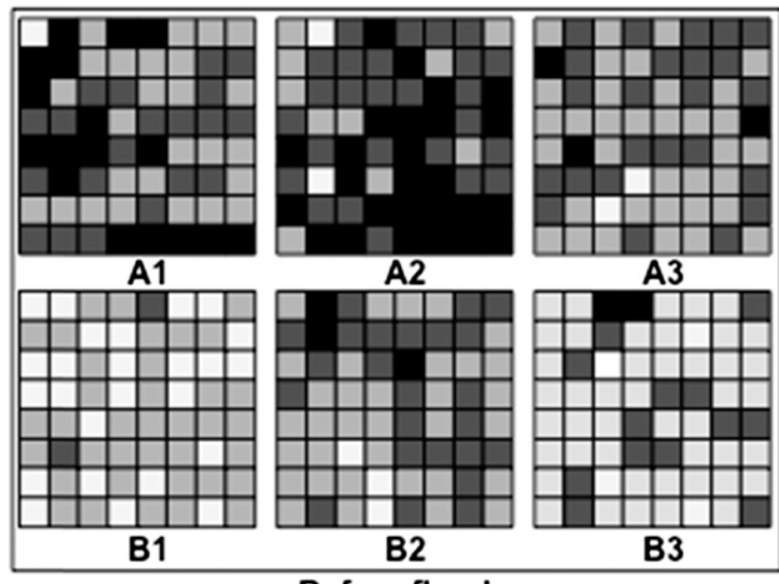

Before flood

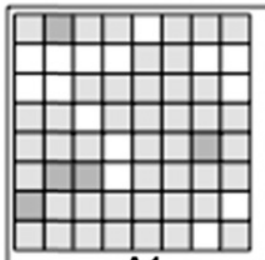

A1

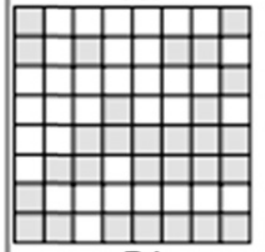

B1

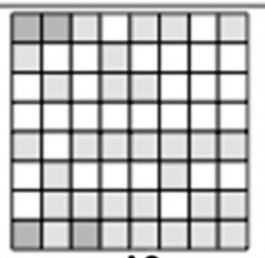

A2

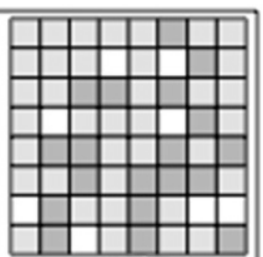

A3

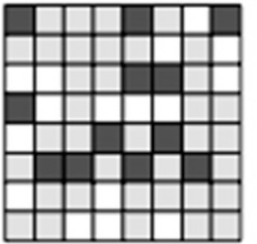

B2

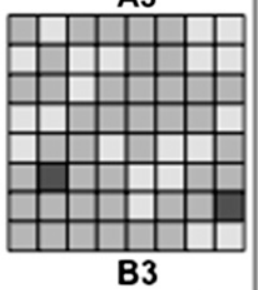

B3

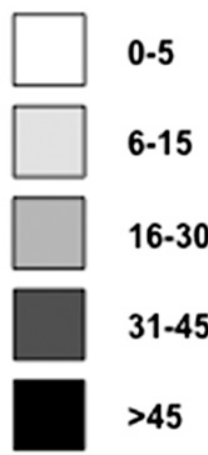

\section{Microsclerotia / g soil}

\section{After flood}

Fig. 4. Verticillium longisporum microsclerotia $\mathrm{g}^{-1}$ of soil estimates within a field in Salinas, CA prior to and following 6 weeks of natural flooding. 
flooding in the Salinas Valley, which experiences a cool Mediterranean climate, occurred throughout spring 1995. Thus, results from this study only partially support previous findings on the efficacy of flood treatments to eliminate this important soilborne pathogen.

In conclusion, quantifying soil levels of ms before and after fumigation with $\mathrm{MeBr}$ and chloropicrin is important to have a baseline for comparative studies on alternative soil treatments and evaluations of their efficacy. This study provides quantitative estimates of the density of residual Verticillium ms which survive in soil postfumigation and differing cropping sequences, and saturation with flood waters.

\section{ACKNOWLEDGMENTS}

Mention of trade names or commercial products in this article is solely for the purpose of providing specific information and does not imply recommendations or endorsement by the U.S. Department of Agriculture. USDA is an equal opportunity provider and employer.

\section{LITERATURE CITED}

1. Atallah, Z. K., Hayes, R. J., and Subbarao, K. V. 2011. Fifteen years of Verticillium wilt of lettuce in America's salad bowl: A tale of immigration, subjugation, and abatement. Plant Dis. 95:784-792.

2. Berbegal, M., Ortega, A., García-Jiménez, J., and Armengol, J. 2007. Inoculum density-disease development relationship in Verticillium wilt of artichoke caused by Verticillium dahliae. Plant Dis. 91:1131-1136.

3. Butterfield, E. J., and DeVay, J. E. 1977. Reassessment of soil assays for Verticillium dahliae. Phytopathology 67:1073-1078.

4. Butterfield, E. J., DeVay, J. E., and Garber, R. H. 1978. The influence of several crop sequences on the incidence of Verticillium wilt of cotton and on the populations of Verticillium dahliae in field soil. Phytopathology 68: $1217-1220$

5. Cirulli, M., Bubici, G., Amenduni, M., Armengol, J., Berbegal, M., Jiménez-Gasco, M. M., and Jiménez-Díaz, R. M. 2010. Verticillium wilt: A threat to artichoke production. Plant Dis. 94:1176-1187.

6. Coley-Smith, J. R., and Cooke, R. C. 1971. Survival and germination of fungal sclerotia. Annu. Rev. Phytopathol. 9:65-92.

7. Duniway, J. M. 2002. Status of chemical alternatives to methyl bromide for pre-plant fumigation of soil. Phytopathology 92:1337-1343.

8. Ebihara, Y., and Uematsu, S. 2014. Survival of strawberry-pathogenic fungi Fusarium oxysporum f. sp. fragariae, Phytophthora cactorum and Verticillium dahliae under anaerobic conditions. J. Gen. Plant Pathol. 80:50-58.

9. Ebihara, Y., Uematsu, S., and Nomiya, S. 2010. Control of Verticillium dahliae at a strawberry nursery by paddy-upland rotation. J. Gen. Plant Pathol. 76:7-20.

10. Gurung, S., Short, D. P. G., Atallah, Z. K., and Subbarao, K. V. 2014. Clonal expansion of Verticillium dahliae in lettuce. Phytopathology 104:641-649.

11. Harris, D. C., and Yang, J. R. 1996. The relationship between the amount of Verticillium dahliae in soil and the incidence of strawberry wilt as a basis for disease risk prediction. Plant Pathol. 45:106-114.

12. Ioannou, N., Schneider, R. W., and Grogan, R. G. 1977. Effect of flooding on the soil gas composition and the production of microsclerotia by Verticillium dahliae in the field. Phytopathology 67:651-656.
13. Koike, S. T., Subbarao, K. V., Davis, R. M., Gordon, T. R., and Hubbard, J. C. 1994. Verticillium wilt of cauliflower in California. Plant Dis. 78: 1116-1121.

14. Littell, R. C., Milliken, G. A., Stroup, W. W., Wolfinger, R. D., and Schabenberger, O. 2006. SAS for Mixed Models. SAS Institute, Cary, NC.

15. Martin, F. N., and Bull, C. T. 2002. Biological approaches for control of root pathogens of strawberry. Phytopathology 92:1356-1362.

16. Matheron, M. E., and Porchas, M. 2005. Influence of soil temperature and moisture on eruptive germination and viability of sclerotia of Sclerotinia minor and S. sclerotiorum. Plant Dis. 89:50-54.

17. McCain, A. H., Raabe, R. D., and Wilhelm, S. 1981. Plants Resistant to or Susceptible to Verticillium Wilt. University of California Leaflet 2703.

18. Menzies, J. D. 1962. Effect of anaerobic fermentation in soil on survival of sclerotia of Verticillium dahliae. (Abstr.) Phytopathology 52:743.

19. Moore, W. D. 1949. Flooding as a means of destroying the sclerotia of Sclerotinia sclerotiorum. Phytopathology 39:920-927.

20. Nadakavukaren, M. J. 1960. The effect of soil moisture and temperature on the survival of Verticillium microsclerotia. $\mathrm{PhD}$ dissert. Oregon State University, Corvallis.

21. Njoroge, S. M., Kabir, Z., Martin, F. N., Koike, S. T., and Subbarao, K. V. 2009. Comparison of crop rotation for Verticillium wilt management and effect on Pythium species in conventional and organic strawberry production. Plant Dis. 93:519-527.

22. Peluola, C., Fernando, W. G. D., Huvenaars, C., Kutcher, H. R., Lahlali, R., and Peng, G. 2013. Effect of flooding on the survival of Leptosphaeria spp. in canola stubble. Plant Pathol. 62:1350-1356.

23. Ponnamperuma, F. 1972. The Chemistry of Submerged Soils, Vol. 24. Academic Press, New York.

24. Powelson, M. L., and Rowe, R. C. 1993. Biology and management of early dying of potatoes. Annu. Rev. Phytopathol. 31:111-126.

25. Powelson, R. 1970. Significance of Population Level of Verticillium in soil. University California Press, Berkeley, CA.

26. Pullman, G. S., and DeVay, J. E. 1981. Effect of soil flooding and paddy rice culture on the survival of Verticillium dahliae and incidence of Verticillium wilt in cotton. Phytopathology 71:1285-1289.

27. Schnathorst, W. 1981. Life cycle and epidemiology of Verticillium. Pages 81-111 in: Fungal Wilt Diseases of Plants. M. E. Mace, A. A. Bell, and C. H. Beckman, eds. Academic Press, New York.

28. Subbarao, K. V. 2002. Introduction. Phytopathology 92:1334-1336.

29. Subbarao, K. V., Vallad, G. E., Qin, Q., Koike, S. T., and Hayes, R. J. 2006. Biology and epidemiology of Verticillium wilt of lettuce. Pages 150-168 in: California Lettuce Res. Board Annu. Rep. California Lettuce Research Board, Salinas, CA.

30. Tjamos, E. C., Rowe, R. C., Heale, J. B., and Fravel, D. R. 2000. Advances in Verticillium Research and Disease Management. The American Phytopathological Society, St. Paul, MN.

31. Wu, B. M., and Subbarao, K. V. 2014. A model for multi-seasonal spread of Verticillium wilt of lettuce. Phytopathology 104:908-917.

32. Xiao, C. L., Hao, J. J., and Subbarao, K. V. 1997. Spatial patterns of microsclerotia of Verticillium dahliae in soil and Verticillium wilt of cauliflower. Phytopathology 87:325-331.

33. Xiao, C. L., and Subbarao, K. V. 1998. Relationships between Verticillium dahliae inoculum density and wilt incidence, severity, and growth of cauliflower. Phytopathology 88:1108-1115.

34. Xiao, C. L., Subbarao, K. V., Schulbach, K., and Koike, S. T. 1998. Effects of crop rotation and irrigation on Verticillium dahliae microsclerotia in soil and wilt in cauliflower. Phytopathology 88:1046-1055. 